\title{
Gerald Edelman
}

\section{(1929-2014)}

\section{Biologist who won Nobel for solving antibody structure.}

$\mathrm{G}$ erald Edelman was a man of diverse talents and broad knowledge. A pre-eminent biologist, he was also an accomplished writer and musician, and read widely in philosophy. This brought an elegant style to his science, and gave his more speculative intellectual works a characteristic literary format.

Edelman died on 17 May in La Jolla, California. Born in Queens, New York, in 1929, he studied medicine. He then turned to immunology and spent most of his research career at Rockefeller University in New York. His focus on the structure of antibodies in the 1960s led to the 1972 Nobel Prize in Physiology or Medicine, which he shared with Rodney Porter. The award recognized Edelman's work on the descriptions of the heavy $(\mathrm{H})$ and light $(\mathrm{L})$ polypeptide chains, and Porter's on the distinct binding domain (antigen-binding or Fab fragment) of antibodies (also called immunoglobulins). These were the first dominoes to fall in the elucidation of the structural variability that lies at the heart of antibody-based recognition of infectious agents such as bacteria and viruses.

With colleague Joseph Gally, Edelman discovered that L-chain polypeptides were secreted in the urine of a person with a myeloma tumour. Being homogeneous (that is, each chain contained a single amino acid sequence), these light chains were amenable to structural characterization, unlike the mixture of antibodies in blood.

After the prize, Edelman's group expanded its interests into several areas, including carbohydrate-binding proteins, cell-to-cell adhesion mediated by proteins on the surface membranes of cells, and tissue morphogenesis. But his personal focus was turning towards the nervous system, leading in 1981 to his founding and direction of the Neurosciences Institute in New York, which he moved with him in 1993 to San Diego, California, where it became part of the Scripps Research Institute (from which it became independent in 2012).

Edelman was fascinated throughout his career by the enormous explanatory potential of selective-recognition systems. These had already been used to attack and elucidate two of the most challenging problems in biology: the evolution of species and the adaptive immune response. Darwinian evolution of species depends on fitness-based selection from a repertoire of variable genetic traits; the immune system recognizes foreign substances by selecting from a repertoire of antigen-recognizing cells.

Over about the same period as the antibody

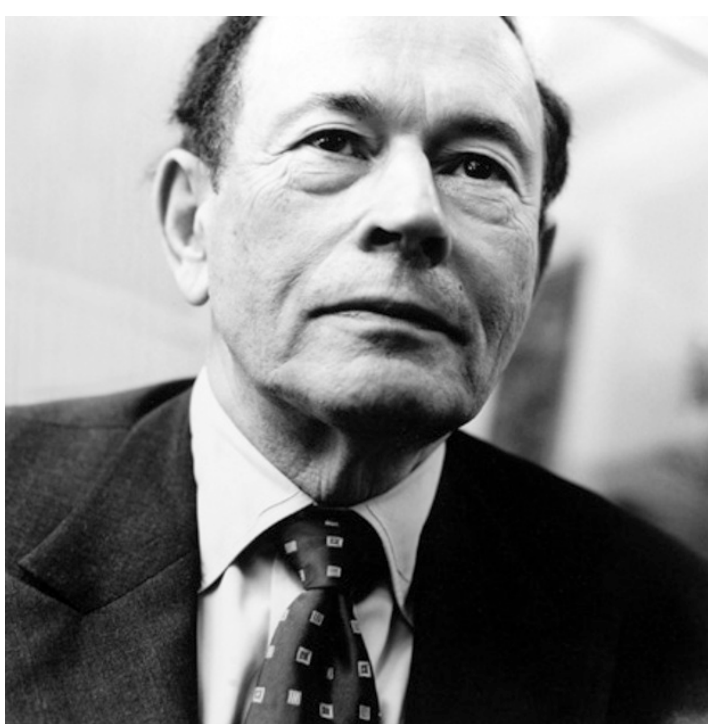

studies, two fundamental properties of neurons and their synaptic connections were discovered by different teams: that cortical neurons are organized into discrete groups of cells, and that synapses strengthen through use. Edelman reasoned that the formidable recognition and processing capabilities of a complex nervous system depend on selection operating on cell groups that differ in their connectivity patterns. Incoming sensory information would elicit a response from distinct cell groups; it could be modified, he posited, by repetitive recognition (termed re-entry) that provided opportunities for strengthening, abstraction and association. Thus, he argued, the simplicity of repeated selection from an evolving repertoire could account for the astonishing information-processing power of sophisticated neural systems.

Edelman presented this idea in several books, including Neural Darwinism (Basic, 1987), Bright Air, Brilliant Fire (Basic, 1993) and A Universe of Consciousness (Basic, 2001), which was written with colleague Giulio Tononi. The descriptions and arguments are often dense and elaborate, viewed by some readers as possessing an admirable literary quality, and by others as redundant and opaque.

Given his multidimensional background and relentless intellect, it is not surprising that
Edelman was a complicated and controversial individual, in his research and his relationships. He could range from charming and inspiring to arrogant and abrupt. Although colleagues often found him abrasive, in his group Edelman could be an effective and generous leader. He sustained collaborations with several prominent scientists, including Gally, Bruce Cunningham whose biochemical skills were essential in the formidable task of antibody analysis in the 1960s and 70s - and George Reeke in the early modelling of selective brain function from the 1980s onwards.

Edelman was also an exceptional mentor. He had a gift for formulating important hypotheses. He instilled a pragmatic attitude towards experimental design: his coinage 'the refrigerator principle' expressed that ideas sometimes come from the ready availability of reagents. He warned of the dangers of distraction - 'don't look sideways' - and stressed the value of interpreting results in a broader context.

Training with him was intense. He once told a senior student: "It's your year, son, to be in the nitric acid sitz bath." Thesis presentations in Rockefeller's legendary Caspary Hall were preceded by weeks of his direct scrutiny - experiences of enduring value to building a research career, and becoming a mentor for the next generation.

With Edelman's passing, there remains the task of testing his theory of selection-based brain function. As with Darwin's species evolution and the adaptive immune response, the theory was proposed before anyone understood the underlying cellular and molecular mechanisms, and before there were adequate analytical tools. There have been some remarkable advances in the past five years in the use of genetics and molecular reporters of synaptic activity that allow real-time evaluation of substantial groups of cells in functioning brain tissue. Thus one can begin to imagine a line of investigation that could address the challenge that his provocative work presents to neuroscience.

Urs Rutishauser is at the Sloan Kettering Institute at the Memorial Sloan Kettering Cancer Center in New York. He was a student and colleague in Gerald Edelman's laboratory at Rockefeller University in New York from 1967 to 1983.

e-mail:u-rutishauser@mskcc.org 